\title{
O CUIDADO À PESSOA MENTALMENTE ADOECIDA E INTERNADA: VIVÊNCIAS E PERCEPÇÕES DA EQUIPE MULTIPROFISSIONAL
}

\section{THE CARE FOR THE MENTALLY ILL AND HOSPITALIZED PERSON: EXPERIENCES AND PERCEPTIONS OF THE MULTIPROFESSIONAL TEAM}

\section{EL CUIDADO DE LA PERSONA MENTALMENTE ENFERMA Y HOSPITALIZADA: EXPERIENCIAS Y PERCEPCIONES DEL EQUIPO MULTIPROFESIONAL}

Bárbara Pereira da Rocha ${ }^{1}$, Camila Cristiane Formaggi Sales², Gabriella Michel dos Santos Benedetti ${ }^{3}$, Tereza Maria Mageroska Vieira ${ }^{4}$, Magda Lucia Félix de Oliveira 5 .

\section{RESUMO}

Objetivo: Compreender as vivências e percepções da equipe multidisciplinar de um hospital psiquiátrico, ao cuidar de pessoas mentalmente adoecidas. Método: Estudo descritivo-exploratório, de abordagem qualitativa, com a participação de 12 profissionais da equipe multiprofissional de um hospital psiquiátrico. O roteiro de coleta de dados, semiestruturado, foi respondido em dois meses. Os relatos foram analisados, por meio da análise de conteúdo. Resultados: Dos relatos emergiram três categorias: Enfrentando desafios ao atuar em um hospital psiquiátrico; Consolidando sentimentos e habilidades a partir do cuidado; Ressignificando o cuidado em um hospital psiquiátrico, por meio das quais se evidenciou que, apesar de inúmeras dificuldades vivenciadas, esse cuidado tem produzido nos profissionais sentimentos de gratidão e satisfação, sobrepondo-se, por vezes, aos desafios experienciados. Novos significados que os fazem dispor de suas habilidades profissionais e pessoais, para qualificar e otimizar a assistência, contribuem para a humanização da assistência. Conclusão: Ressaltam-se dificuldades estruturais, como fontes adicionais de financiamento, para o suprimento de recursos humanos e materiais, com vistas a minimizar o excesso de carga de atividades, valorização do trabalho realizado e reconhecimento dos profissionais.

Palavras-chave: Hospitais Psiquiátricos; Empatia; Pessoal de Saúde; Equipe de Assistência ao Paciente.

\begin{abstract}
Objective: To understand the experiences and perceptions of the multidisciplinary team of a psychiatric hospital that provides care for individuals with mental illness. Method: Descriptive-exploratory, qualitative study carried out with 12 professionals of a multiprofessional team of a psychiatric hospital. Semi-structured interviews were made in two months. Data analysis was performed using content analysis. Results: From the reports, three categories occurred: Facing challenges from working in a psychiatric hospital; Consolidating feelings and skills from providing care and, Giving a new meaning to the care provided in a psychiatric hospital. Despite many difficulties, the professionals experienced feelings of gratitude and satisfaction, sometimes overcoming the challenges. In addition these new meanings enhance professional skills to qualify and optimize care, and their human dimensions, contributing to the humanization of care. Conclusion: There is an urgent need for other sources of financing for the supply of human and material resources, to minimize the overload of activities, value the professionals and their work performed.
\end{abstract}

Keywords: Hospitals, Psychiatrics; Empathy; Health Personnel; Patient Care Team.

\section{RESUMEN}

Objetivo: comprender las experiencias y percepciones del equipo multidisciplinario de un hospital psiquiátrico que atiende a personas con enfermedades mentales. Método: Estudio descriptivo-exploratorio, con enfoque cualitativo, realizado con 12 profesionales del equipo multidisciplinario de un hospital psiquiátrico. Los guiones de la entrevista semiestructurada fueron respondidos en dos meses. El análisis de datos se realizó a través del análisis de contenido. Resultados: Del análisis de los relatos surgieron tres categorías: enfrentar desafíos cuando se trabaja en un hospital psiquiátrico; Consolidando sentimientos y habilidades en función de la atención realizada y, redefiniendo la atención que realizan en el hospital psiquiátrico, a través de la cual se demostró que a pesar de las numerosas dificultades experimentadas, esta atención ha producido sentimientos de gratitud y satisfacción en los profesionales, anteponiendose, a veces, a los desafíos experimentados, además de encender nuevos significados que los hacen tener, no solo sus habilidades profesionales para calificar y optimizar la atención, sino también sus dimensiones humanas, lo que ha contribuido a la humanización de la atención. Conclusión: Se enfatiza la necesidad de otras fuentes de financiamiento, para el suministro de recursos humanos y materiales, a fin de minimizar la sobrecarga de actividades, la valorización del trabajo realizado y el reconocimiento de los profesionales.

Descriptores: Hospitales Psiquiátricos; Empatía; Personal de Salud; Grupo de Atención al Paciente.

${ }^{1}$ Mestranda do Programa de Pós-Graduação em Enfermagem na Universidade Estadual da Maringá. ${ }^{2}$ Mestre e Doutoranda em Enfermagem pelo Programa de Pósgraduação em Enfermagem da Universidade Estadual de Maringá. ${ }^{3}$ Mestre e Doutoranda em Enfermagem pelo Programa de Pós-graduação em Enfermagem da Universidade Estadual de Maringá. ${ }^{4}$ Mestre em Enfermagem pela Universidade Estadual de Maringá. ${ }^{5}$ Doutora em Saúde Coletiva pela Universidade Estadual de Campinas. 


\section{INTRODUÇÃO}

O ser humano é dotado de subjetividade e singularidade complexas, expressas por meio de sua historicidade, de um seio familiar ao qual pertence, de hábitos, valores e crenças culturalmente construídos, de direitos e responsabilidades ante ao mundo e às pessoas que o cercam e de inúmeros papéis que assume como pais, filhos, profissionais, entre outros. Autoimagem, autorrealização, liberdade, sentimentos, saúde e capacidade de transcender o momento vivido também influenciam o viver humano e, quando uma dessas dimensões encontra-se fragilizada, impossibilitando a pessoa de gozar do bem-estar pleno, o sofrimento advém ${ }^{(1)}$.

Frente ao sofrimento ou transtorno mental, a pessoa precisará de cuidados específicos que. na legilação brasileira estão regulamentados na Portaria N. 3.588, de 21 de dezembro de 2017, em uma Rede de Atenção Psicossocial - RAPS. Por meio desta, a pessoa, mentalmente adoecida, deverá receber atenção integral, efetiva e articulada entre os pontos de atenção à saúde. Nesse aspecto, são enfatizados os serviços de nível comunitário e base territorial, que possibilitem a inclusão social dessa pessoa, para a promoção de sua autonomia e cidadania, bem como sua participação e controle social da atenção ofertada ${ }^{(2)}$.

Apenas quando os recursos extrahospitalares não se mostrarem suficientes para atender às necessidades de saúde da pessoa em sofrimento mental, esta deverá ser conduzida ao internamento, em leitos em hospital geral ou em hospital psiquiátrico. Considerando-se que são proibidas internações dessa natureza em instituições similares a asilos, a pessoa deve retornar aos serviços comunitários de saúde mental logo que possível(3). Ressalta-se que, atualmente, os hospitais psiquiátricos não representam a primeira opção para esse tipo de tratamento, porém verifica-se que ainda são frequentemente acionados pela rede de atenção psicossocial, especialmente para aqueles que necessitam da intensificação do acompanhamento, por um curto período de tempo ${ }^{(4)}$.

Para atender, integralmente, às necessidades da pessoa portadora de doença mental em situação de internamento, os hospitais psiquiátricos devem dispor de equipe técnica multiprofissional composta por enfermeiro e outros profissionais de enfermagem, médico, assistente social, psicólogo, farmacêutico, nutricionista, educador físico, terapeuta ocupacional, terapeuta de lazer, atividade desempenhada no hospital por um pedagogo, entre outros que se fizerem necessários. Dessa maneira, poderá garantir a qualidade do serviço e disponibilizar cuidado integral e multiprofissional ${ }^{(2-3)}$.

Por ocasião da internação, a pessoa encontra-se fragilizada, por vezes com o pensamento desorganizado, com dificuldades em cuidar de si ou sob efeito de medicações, por isso, necessitará da atenção de uma equipe multiprofissional capaz de organizar o cuidado e atendê-lo em suas singulares e complexas demandas, que são determinadas por diversos fatores e, em especial, frente aos sinais e sintomas manifestados ${ }^{(5)}$. Profissionais que atuam em hospital psiquiátrico percebem a necessidade de estar disponíveis, oferecer escuta qualificada, acolher e gostar do que faz em prol da efetivação do cuidado, mas que o trabalho em equipe fica prejudicado ante a dificuldade que alguns profissionais têm em se adaptar as novas diretrizes de cuidado em saúde mental, com base na atual política de atenção psicossocial(6-7).

A literatura apresenta que esses profissionais enfrentam dificuldades ao realizar o cuidado no contexto hospitalar psiquiátrico ${ }^{(5,6,7)}$. Problemas relacionados à falta de incentivo financeiro dos órgãos públicos, falta de profissionais da área, número reduzido de profissionais nas equipes em atividade e o alto índice de reinternações ${ }^{(6)}$, o que pode causar falta de motivação, sobrecarga à equipe e, comprometer a qualidade do cuidado.

Discute-se, também, que os profissionais não têm sido preparados para atuarem nesse contexto de cuidado, logo aprendem com a própria prática cotidiana, e sofrem preconceito ante ao estigma socialmente construído em torno do cuidado de pessoas mentalmente adoecidas e ficam mais expostos ao estresse físico e emocional suscitado pelo ambiente de trabalho( ${ }^{(5)}$.

Ao considerar que conhecer tais aspectos, na percepção dos próprios profissionais, poderá fornecer subsídios para a implementação de ações que venham a fortalecer as potencialidades identificadas e minimizar as fragilidades do cuidado, e possibilitar o desenvolvimento de habilidades pessoais/profissionais, questiona-se: como a equipe multiprofissional tem vivenciado e percebido o cuidado ao paciente psiquiátrico internado? 
Diante do exposto, objetivou-se, com este estudo, compreender as vivências e percepções da equipe multidisciplinar de um hospital psiquiátrico, ao cuidar de indivíduos mentalmente adoecidos.

\section{MÉTODOS}

Trata-se de estudo descritivo, exploratório, realizado em um hospital psiquiátrico filantrópico na região Noroeste do Estado do Paraná, envolvendo profissionais de nível técnico e de nível superior que compõem a equipe multiprofissional de saúde do hospital.

Em março de 2018, a Diretoria do hospital forneceu uma lista impressa com a relação de todos os profissionais da institução aos pesquisadores, que permaneceram no hospital por um dia para observação institucional e aproximação com os profissionais, com esclarecimentos quanto à pesquisa e convite para participação. A partir desse procedimento, todos os profissionais que atuavam no hospital psiquiátrico, foram formalmente convidados pelas pesquisadoras a participar da pesquisa.

Foram incluídos profissionais que atuavam nos quatro turnos de trabalho (matutino, vespertino, noturno um e noturno dois) por, no mínimo, seis meses, pois se considerou esse período de tempo como adequado para 0 profissional descrever suas percepções e vivências com o paciente internado. Profissionais que estivessem afastados da atividade no período de coleta de dados - férias, licença saúde, licençamaternidade, licença especial ou outro tipo de afastamento legal, foram excluidos. Dos 20 profissionais elencados pela administração do hospital, um não atendeu ao critério de inclusão e sete se recusaram a participar do estudo, o que resultou em 12 participantes.

O instrumento de coleta foi um roteiro semiestruturado e autoaplicável, composto de questões para caracterização sociodemográfica e profissional dos participantes, com a finalidade de traçar o perfil dos participantes, e questões norteadoras/ abertas, relacionadas ao processo de trabalho e vivências e percepções profissionais. Salienta-se que ao abordar os demais profissionais que compunham a equipe multiprofissional e que não eram da categoria profissional da enfermagem, o termo "cuidado" foi adequado e substituído por "tratamento", inclusive para o terapeuta de lazer/pedagogo.

A coleta de dados se deu nos meses de abril e maio de 2018 , sob supervisão de uma docente de enfermagem que atuava na instituição e que foi capacitada para a atividade. Após a abordagem inicial a todos os profissionais que atuavam no hospital, os procedimentos de coleta de dados eram explicados aos que aceitaram participar da pesquisa, esclarecendo possíveis dúvidas sobre a participação.

O roteiro, acompanhado de nota explicativa e duas cópias do termo de consentimento livre e esclarecido (TCLE), foi distribuído aos profissionais em seu local de trabalho, em envelopes individuais e respondido de forma escrita, em uma sala privativa, após a assinatura do TCLE. Após esses procedimentos, os envelopes individuais foram lacrados pelo próprio profissional e recolhidos pela docente supervisora.

A utilização do roteiro autoaplicável e anônimo possibilitou aos participantes descrever livremente suas vivências e percepções sobre a temática abordada, sem inibi-los diante do medo de sofrer represálias e/ou de ser interrompido quando estivesse participando da pesquisa, visto que o estudo abordava questões relacionadas ao ambiente de trabalhos dos profissionais. A média de tempo para respostas foi de, aproximadamente, 30 minutos, estabelecida pelo tempo de entrada e saída da sala privativa utilizada pelos respondentes.

Os dados de caracterização dos profissionais foram compilados em planilha eletrônica no Software Microsoft Office Excel 10.0, analisados descritivamente. Os dados foram transcritos na íntegra, digitados em documento de texto utilizando o Software Microsoft Office Word 10.0, analisadas utilizando-se a técnica de análise de conteúdo, que consiste em um conjunto de técnicas de análise das comunicações que utiliza procedimentos sistemáticos e objetivos de descrição do conteúdo das mensagens, sendo dirigida pelos seguintes passos: 1) pré-análise; 2 ) exploração do material; e 3) inferência e interpretação(8).

$\mathrm{Na}$ etapa de pré-análise, houve leituras exaustivas dos relatos dos participantes do estudo, a fim de conhecer o texto e possibilitar a imersão em seu conteúdo, permitindo maior apreensão do todo apresentado. Em um segundo momento, na etapa de exploração do material, transcorreu a codificação dos dados brutos, transformando os relatos em informações significativas. É nessa etapa que se realizou a exploração do material e a associação das informações produzidas, o que originou as unidades de registro. Em seguida, efetivou-se o 
processo, por meio da análise temática, a qual gerou os núcleos de sentido, onde sua aparição e repetição foram consideradas. $E$, à medida que esses núcleos se reuniram por aproximação de seus significados, nasceram às categorias. Por fim, em um terceiro momento, na etapa de inferência $e$ interpretação, com base nos discursos utilizaram-se as variáveis de inferência para, assim, elaborar as interpretações ${ }^{(8)}$.

Por se tratar de um estudo realizado com seres humanos, foram respeitados os preceitos éticos. O projeto foi aprovado pelo Comitê de Ética e Pesquisa com Seres Humanos sob o parecer $\mathrm{n}^{\circ}$ 2.569.659/2018 e Certificado de Apresentação para Apreciação Ética (CAAE) $n^{\circ}$ 84063918.0.0000.0104. A fim de manter o sigilo quanto às informações prestadas e anonimato sempre que os resultados forem divulgados, os participantes foram nominados com a letra $P$ (profissionais), seguida de numeral arábico na sequência em que os roteiros foram respondidos.

\section{RESULTADOS E DISCUSSÃO}

Participaram do estudo 12 profissionais: dois enfermeiros, quatro técnicos em enfermagem, um médico psiquiatra, um psicólogo, um pedagogo/terapeuta de lazer, um assistente social, um nutricionista e um farmacêutico. Destes, dez eram do sexo feminino, a idade variou entre 22 e 63 anos com média de 35 anos. A renda profissional variou entre um salário mínimo e meio e 10 salários mínimos e meio do período de coleta de dados. O tempo de formação profissional era em média 15 anos e o tempo de experiência profissional no hospital psiquiátrico variou entre um e 27 anos.

A partir da análise de conteúdo dos relatos, emergiram as categorias: Enfrentando desafios ao atuar em hospital psiquiátrico, Consolidando sentimentos e habilidades a partir do cuidado e, Ressignificando o cuidado no hospital psiquiátrico.

\section{Enfrentando desafios ao atuar em hospital psiquiátrico}

Trabalhar em hospitais psiquiátricos pode gerar momentos de tensão, sobrecarga e estresse. Alguns participantes relataram que a falta de funcionários, o excesso de atividades burocráticas e os riscos de violência verbal e física são fatores condicionantes dos sentimentos citados acima, considerando que, geralmente, as pessoas internadas nessas instituições estão com o quadro de sua doença agravado.
Para P2, o dia a dia de trabalho em um hospital psiquiátrico tem demandado habilidades técnicas e emocionais específicas, por parte dos profissionais que, por vezes, percebem um alto grau de exigência sobre suas tarefas como um desafio a ser superado.

"É uma rotina que exige muito do profissional, principalmente os profissionais da enfermagem, pois além dos cuidados realizados com os pacientes internados [...] tem as intercorrências, sejam elas clínicas ou psiquiátricas, como nos casos de encaminhar o paciente à sala de observação, medicá-lo e contêlo no leito, quando necessário. Além de realizar internamento, ou seja, admitir novos clientes, entrevistar as suas famílias, sem contar as atividades burocráticas, como acessar o sistema (Central de Leitos), registrar nos prontuários dos pacientes, fazer escala de funcionários, ou seja, exige muita atenção, dedicação e paciência para lidar com toda essa situação" (P2).

O excesso de tarefas para o tempo que dispõem, especialmente no que se refere às atividades burocráticas e administrativas, pode distanciar os profissionais do contato com os pacientes, fazer com que se sintam pressionados e, consequentemente ansiosos ${ }^{(9)}$.

Em meio a uma rotina diária agitada, surgiu como um desafio para alguns profissionais relacionar-se, terapeuticamente, com os pacientes internados por dependência química.

"[...] dependentes químicos é mais difícil, pois são totalmente orientados e dissimulados, trazendo conflitos ao ambiente e aos pacientes de transtorno" (P11).

"Se tratando de pacientes com transtorno, não vejo dificuldade alguma sou muito feliz e realizada em minha profissão. Agora quando se trata de pacientes com dependências químicas e orientados e não querem o tratamento, esses sim, me sinto incapaz e com várias dificuldades, pois são manipuladores e nada que fazemos está bom, só reclamam, não está sendo fácil” (P10).

"[...] hoje está muito difícil lidar com os pacientes, principalmente os dependentes químicos, que querem ditar as regras deles dentro da instituição, isso é ameaçador, pois ficamos à mercê deles, são a maioria dentro do hospital isso gera desconforto, medo, insegurança, noites mal dormidas e vontade de abandonar a profissão. Triste, porém real" (P2).

Os relatos dos profissionais revelaram que estão, constantemente, com medo de serem agredidos de forma violenta pelos indivíduos 
internados por dependência química. Nesse aspecto, evidenciou-se que os participantes se sentem inseguros, amedrontados, pouco valorizados e apoiados ante os desafios vivenciados, principalmente quando a assistência é voltada ao dependente químico. Não se podenegar que a exposição à violência, no ambiente de trabalho, pode trazer significativos prejuízos para a prática cotidiana dos profissionais de saúde, comprometendo sua percepção acerca da própria satisfação e de reconhecimento do seu trabalho, bem como o distanciamento profissional no que tange ao relacionamento terapêutico. Com isso, podem viver sofrimentos diversos e desenvolver transtornos psíquicos, fazendo-se necessário implementar ações que reprimam os atos violentos e minimizem os desgastes sofridos pelos membros da equipe ${ }^{(10-11)}$.

Muitos pacientes internados por dependência química apresentam passagens pela polícia e são internados compulsoriamente, via mandados judiciais, em razão do envolvimento prévio com a criminalidade e comportamento de risco para a sociedade e para si próprio, refletindo no medo relatado pelos participantes. Nesse aspecto, os cuidados específicos voltados para esse público ainda não se encontram totalmente consolidados, envolvendo preconceito e estigma, mas não se pode perder de vista a necessidade de elaborar estratégias que visem à reinserção desses indivíduos na sociedade (12), pois a lógica repressiva coloca o acento na droga, resultando em baixa resolutividade na atenção à pessoa necessitada.

“Na época da graduação, eu sempre gostei e me identifiquei com a área da saúde mental/psiquiatria, hoje atuando na área há 1 ano e 4 meses, eu tenho outra perspectiva, é um trabalho muito desgastante e estressante, sem contar a desvalorização profissional, e os riscos envolvidos como violência verbal e física" (P2).

"Os pacientes mentalmente adoecidos, cuido com o maior prazer, agora os dependentes químicos e que não querem tratamento, esses estão difíceis, pois estamos sendo indiscriminadamente agredidos verbalmente $\mathrm{e}$ nada está sendo feito" (P10).

"Não tenho muita paciência para lidar com paciente dependente químico. Trabalhar sob pressão, sem respaldo algum" (P11).

Diante dessas falas, traz-se uma discussão importante na abordagem ao paciente internado por dependência química, observando estigma, durante a assistência prestada pelos profissionais da equipe multiprofissional quando eles citam a diferença entre a dependência química e as demais doenças mentais. Autores (13-14) consideram o estigma como expressão de violência, onde os profissionais estão inseridos em relações de poder. Portanto, considera-se que, como parte desse sistema de poder e hierarquias, que segrega as diferenças, tais profissionais não identificam estigma como expressão de violência e nem o percebem como facilitador para o agravamento dos transtornos mentais ${ }^{(14)}$.

Tal prática entreabre a possibilidade de uma concepção moral da assistência a qual se baseia no julgamento tácito definindo quem merece ou não. Situações dessa natureza, por vezes, correspondem a práticas clínicas ofertadas de maneira compulsória, envolvendo descasos, incapacidade de escuta ou até negligência, sendo fortemente relacionada com o proibicionismo e a demonização das drogas, constituído como um fator social, criando o estigma de que o dependente químico está transgredindo os padrões da sociedade. A associação que envolve a ilegalidade ao uso dessas substâncias, faz com que esses usuários sejam vistos como criminosos e, portanto, não portadores de problemas de saúde (12).

A falta de experiência e de preparo para atuar no contexto psiquiátrico também representou um desafio evidenciado na análise e mencionado por alguns dos profissionais respondentes.

"A falta de experiência na parte clínicamédica" (P2).

"Uma das minhas fragilidades perante $\mathrm{O}$ cuidado do paciente é a sua resistência ao tratamento. Desse modo, sinto falha em saber como lidar" (P7).

A assistência ao paciente psiquiátrico deve ser pautada no conhecimento das políticas e legislações vigentes, nesse âmbito e em embasamento científico, a fim de que se ofereça uma atenção adequada e de qualidade. Estudo realizado em um hospital geral de um município do Piauí, Brasil, aponta que a maioria dos enfermeiros não se sente capacitada para atuar em tal contexto. Logo, a busca de conhecimento por meio das modalidades de educação, representa uma maneira viável para que as dúvidas sejam esclarecidas acerca dos cuidados com o paciente mentalmente adoecido e dos protocolos a serem estabelecidos e utilizados ${ }^{(15)}$.

Ressalta-se a disponibilização de atividades de capacitação e um olhar mais humanizado com 
a equipe multidisciplinar, como mecanismo para a diminuição do quadro de desafios apresentados, pois uma vez que os gestores tomem conhecimento das fragilidades e potencialidades de sua equipe, poderão implementar ações que oportunizem a capacitação desses profissionais. Dessa maneira, mesmo diante das particularidades vivenciadas, eles poderão ser envolvidos no processo de cuidado, aprimorar sua prática e torná-la mais resolutiva.

Os profissionais apontaram ainda que, apesar de estarem satisfeitos com o trabalho que realizam e reconhecerem sua importância, o déficit de recursos materiais e humanos têm representado um desafio em sua prática cotidiana. A remuneração insuficiente e a falta de segurança em situações arriscadas, em decorrência do número reduzido de profissionais nas equipes dos plantões, são necessidades não atendidas.

"São muito bem tratados, sob os cuidados de toda equipe multidisciplinar, apesar das dificuldades que a própria unidade de saúde enfrenta, devido sua forma filantrópica" (P3).

"Não são fáceis (os dias de trabalho), às vezes faltam recursos, porém prazeroso, pois entendo a necessidade dos pacientes e familiares" (P12).

"Me sinto bem fazendo meu trabalho, porém uma certa preocupação com a falta de segurança, principalmente para quem trabalha no período noturno. Já que nosso segurança só fica até a meia noite e quando vai embora, o restante da noite ficamos só, quer dizer um enfermeiro e o técnico para cuidar de 48 pacientes[...]. Sem dizer da baixa remuneração que ganhamos trabalhando aqui [...]" (P9).

Os profissionais entrevistados atuam em um hospital filantrópico, mantido por entidade religiosa. Os hospitais filantrópicos apresentam certa fragilidade econômica e de gerenciamento, o que coloca em risco sua sobrevivência, bem como o suporte que representam dentro do Sistema Único de Saúde, já que prestam serviços especializados e, por vezes, são os únicos prestadores quando se trata de municípios do interior dos Estados, logo têm reconhecida e fundamental importância para o contexto de assistência em saúde mental ${ }^{(16)}$. Entretanto, o déficit de pessoal e funcionários, em proporções inadequadas para atender o número de pacientes internados, por sua vez, pode aumentar o estresse do pessoal reduzindo sua capacidade de atender às necessidades de todos os doentes sob seus cuidados $^{(17)}$. Com isso, as pessoas internadas podem ter seus quadros agravados, e se expressarem, por meio da agressividade para com a equipe multiprofissional e demais pacientes ${ }^{(18)}$.

Ressalta-se que o gerenciamento de pessoal dentro de instituições hospitalares representa um grande desafio, entretanto não se pode perder de vista a importância de uma gestão baseada nos preceitos da humanização, valorizando o profissional e reconhecendo suas dimensões humanas ${ }^{(19)}$.

Diante do exposto, verifica-se que os desafios apresentados até 0 momento corroboram com os achados de estudo recente que apontam que o estresse ocupacional pode estar relacionado a questões organizacionais da instituição quando apresentam o comprometimento das condições de trabalho, falta de valorização dos profissionais, falta de satisfação e motivação para o trabalho, redução do número de pessoal e baixas remunerações ${ }^{(20)}$.

Nesse aspecto, cabe rever as fontes de financiamento, reavaliar o emprego dos recursos e considerar a contratação de novos funcionários, visando a minimizar a sobrecarga de trabalho. E, sobretudo, primar pelo envolvimento da equipe no processo de cuidado e sua capacitação para a prática com vistas à valorização e motivação dos profissionais atuantes.

O processo de formação em saúde mental, seja a formação acadêmica ou mesmo as estratégias de capacitação e aperfeiçoamento nos serviços, implementadas sob a forma de educação permanente, é apontado como mola motriz para a superação de desafios elencados, dentre eles o trabalho em equipe e sua melhor atuação e articulação no cenário psicossocial. Reconhece-se a necessidade de maiores esforços no incentivo à qualificação em saúde mental, voltada aos profissionais, como uma estratégia para o fortalecimento das políticas públicas e intervenções nesse campo, consolidando-se, sobretudo, práticas inovadoras de educação permanente entre os serviços.

\section{Consolidando sentimentos e habilidades a partir do cuidado}

Cuidar de pacientes internados numa instituição psiquiátrica pode fazer emergir variados sentimentos, percepções e comportamentos nos profissionais que os assistem. Evidenciou-se que a frustração e a sensação de impotência ganham destaque nesse cenário, em decorrência, principalmente, da falta 
de resolutividade das ações implementadas e pelas fragilidades existentes no manejo dos casos dentro da rede de atenção.

"[...] tem aqueles pacientes que após saírem da internação voltam novamente ao problema que fizeram os mesmos a se internarem, como é o caso dos pacientes dependentes químicos e transtornos mais severos. Falta dar continuidade ao tratamento no domicílio, acompanhamento por parte das equipes de estratégia de saúde da família, falta esse elo entre tais instituições, o que deixa um sentimento de frustração em nós profissionais" (P2).

"Eu me sinto realizado quando vejo melhora progressivamente do paciente. Quando não, gera um sentimento de impotência [...]" (P11).

As reinternações em hospitais psiquiátricos têm se mostrado frequentes e recorrentes, especialmente pela falta de continuidade do cuidado e de comunicação/integração entre os dispositivos da rede de atenção psicossocial. Isso gera uma demanda excessiva e hospitais psiquiátricos superlotados, o que revela a necessidade de uma maior articulação entre as ações desenvolvidas pela Atenção Básica com as dos demais dispositivos da rede, especialmente com as instituições hospitalares ${ }^{(6)}$.

No que se refere ao sentimento de fracasso dos profissionais, a literatura aponta que desenvolver habilidades terapêuticas, dar a necessária importância ao trabalho em equipe e superar os preconceitos que abarcam o contexto psicossocial, pode auxiliá-los a superar as dificuldades vivenciadas em sua pratica cotidiana de trabalho ${ }^{(5)}$.

Nesse aspecto, apesar dos desafios e frustrações enfrentados, sentimentos positivos emergiram do cuidado ofertado ao indivíduo mentalmente adoecido institucionalizado. Atender às necessidades dessas pessoas e contribuir de alguma forma com seu tratamento tem trazido satisfação para os profissionais.

"Me sinto feliz e realizada podendo ajudálos, pois sei que fiz algo bom e vou para casa tranquila em saber que deixei alguém feliz. Faço tudo o que puder para eles, pois amo o que faço e também amo trabalhar com os pacientes" (P1).

"Me sinto bem. Acredito que esteja acrescentando algo para a vida deles, mesmo quando as mudanças não acontecem" (P4).

"É gratificante, pois são pessoas que necessitam de carinho, atenção, além dos cuidados clínicos e psiquiátricos para a estabilização do seu quadro. Muitas vezes percebemos que o carinho para com eles tem contribuído muito para a melhora do quadro" (P6).

As relações entre pacientes e equipe multiprofissional oportunizadas por uma interação positiva, entre ambos, em nível pessoal, e da equipe com o ambiente de trabalho, ocasionam satisfação no trabalho ${ }^{(18)}$. Para tanto, é necessário que os profissionais de saúde atentem para as necessidades das pessoas adoecidas mentalmente e suas expressões de evolução, para ajustar os cuidados conforme a atual situação clínica. Essa abertura para as expressões do outro cria momentos de consolidação de uma ajuda concreta e faz as pessoas se sentirem melhor. ${ }^{(22)}$.

Ainda, nesse contexto, os relatos dos profissionais revelaram que os mesmos se sentem recompensados ao testemunharem a evolução do paciente. Com a sensação de missão cumprida, têm percebido a possibilidade de o paciente retomar a direção de sua vida e as famílias satisfeitas com o cuidado ofertado.

“[...] é estressante, desgastante, a desvalorização profissional é presente todos os dias, mas quando objetivo é atingido e a melhora do paciente é evidente, vale à pena no final" (P2).

"É gratificante ver a evolução do tratamento oferecido, principalmente na alta do paciente. A satisfação familiar para o profissional é muito gratificante" (P5).

"Ver a evolução do paciente é maravilhoso, observar como ele chegou e vê-lo saindo bem e disposto a cuidar de sua saúde mental é muito honroso para mim" (P7).

Não obstante, elementos da comunicação foram valorizados pelos participantes com vistas a construir um ambiente que oportunize o diálogo onde o doente possa manifestar suas angústias e expectativas e, o profissional possa estar atento às suas reais necessidades e intervir de forma mais resolutiva.

"[...] ouvir o que o paciente tem para dizer. Muitas vezes, devido ao estresse que a doença gera na família, eles ficam sem paciência em ouvilos e aqui conseguimos deixar com que eles falem, desabafem" (P6).

"[...] sinto-me mais aberta e humanizada para lidar com o paciente mentalmente adoecido, portanto busco muito a conversação e a confiança do paciente em mim, para que assim eles possam estar mais abertos para o tratamento" (P7). 
Os processos de comunicação que ocorrem de forma efetiva entre profissionais de saúde e pacientes mentalmente adoecidos institucionalizados permitem que o doente perceba a preocupação da equipe com seu bem-estar, se sinta mais seguro e se envolva de forma mais ativa em seu plano de cuidados ${ }^{(22)}$. Diante disso, os pacientes passam a dar significativa importância às equipes que se comunicam com excelência e possuem habilidades de escuta e de manejo dos cuidados, especialmente aquelas que permitem que os pacientes verbalizem seus sentimentos. ${ }^{(18)}$.

A empatia, a paciência, a calma e a estabilidade emocional também representaram habilidades indispensáveis no trato com o paciente psiquiátrico institucionalizado, conforme os relatos a seguir:

"Sou atenciosa, sei ouvi-los, compreender seu problema" (P11).

"Consigo me abrir e conversar muito, me coloco no lugar deles e também tenho facilidade em fazer brincadeiras com eles, tornando assim o trabalho mais agradável" (P1).

"No início, eu tinha muito medo de lidar com esses pacientes, pois não sabia como abordálos. Hoje já não é assim, aprendi a lidar com eles como chamar a atenção, como colocar limites para que eles tenham respeito para com a equipe e demais clientes, e para conquistar esse voto de confiança precisamos ser flexíveis, entender o lado deles, ter empatia [...]" (P2).

"No meu ponto de vista é a paciência e calma no qual essa profissão exige muito" (P3).

"O cuidado para com os pacientes mentalmente adoecidos nesta instituição é um trabalho que exige muita dedicação e paciência por parte dos colaboradores, pois ele necessita muitas vezes de cuidados como dar banho, alimentação na boca até que esse paciente se encontre em condições psiquiátricas de realizar os cuidados pessoais sozinho" (P6).

Comportamentos e atitudes como ser dedicado e paciente, bem como flexível, ágil e prudente são essenciais para os profissionais que atuam no contexto de saúde mental, especialmente no que diz respeito à criação de vínculos com os doentes ${ }^{(5)}$. O cuidado realizado de forma humanizada demonstrou o respeito e a preocupação que os profissionais têm com as dimensões humanas e em oferecer uma atenção de qualidade.

Colocar-se no lugar do outro e buscar compreendê-lo no momento vivido faz emergir o sentimento de compaixão entre os profissionais, 0 que pode contribuir para a efetivação de um cuidado mais humano. Tais atitudes podem ainda favorecer os relacionamentos terapêuticos, até mesmo em situações conflituosas, as quais demandam uma postura madura e assertiva diante de um evento estressor ${ }^{(19)}$.

Frente ao exposto, superar as frustrações e os desafios experienciados no cotidiano de cuidado do paciente psiquiátrico, por meio de atitudes positivas, pode fortalecer as relações terapêuticas. Logo, o amadurecimento dos sentimentos e o desenvolvimento de habilidades se revelam como elementos fundamentais para a realização do cuidado nesse contexto.

\section{Ressignificando o cuidado no hospital psiquiátrico}

Ao serem questionados sobre o que significa cuidar do paciente mentalmente adoecido internado em hospital psiquiátrico, os participantes manifestaram suas diversas percepções ao assistir a esse grupo, discursando sobre os significados que emergem de sua prática cotidiana.

Para alguns profissionais realizar esse cuidado representou auxiliar o doente a buscar motivação para as transformações necessárias, repensar o sentido da vida e reocupar o seu papel no seio familiar e na sociedade.

"Significa deixá-los felizes, confortáveis e com vontade de mudar de vida. Muitos perdem o ânimo, a vontade de viver por um ou outro motivo, e eu como profissional podendo de uma forma ajudar, orientar essa pessoa a pensar ou agir diferente, voltar ao seio de sua família, pois muitos perdem o contato e conseguimos fortalecer esses vínculos" (P1).

"Significa fazer toda a diferença naquele momento em que estão totalmente desacolhidos pela família, sociedade, seja pela sua atual situação ou de qualquer outra" (P4).

Nesse aspecto, estudo recente realizado na Noruega aponta que receber cuidados de saúde mental pode ajudar as pessoas a se sentirem melhor e fortalecem sua autoestima dia após dia, fazendo com que se sintam importantes para outras pessoas. Além disso, desperta sua atenção para as próprias necessidades, tornando-os conscientes da importância de lutar pela recuperação de sua saúde ${ }^{(22)}$.

Para P12, prestar assistência à pessoa mentalmente adoecida consiste em dar o melhor de si em prol do outro, lançando mão não apenas 
de suas habilidades técnicas, mas de suas dimensões humanas para a efetivação do cuidado.

"Profissionalmente significa buscar a melhor forma de realizar meu trabalho, potencializando a melhora de cada paciente. Pessoalmente acredito ainda no amor ao próximo" (P12).

Pessoas em fases agudas da doença mental apresentam necessidades de cuidados específicos que mudam constantemente, dependendo do momento vivido. Esse contexto exige dos profissionais conhecimento específico, sensibilidade, habilidades diversas e comprometimento que vão além das diretrizes padronizadas, já que cada indivíduo experiencia doenças da mente de forma única ${ }^{(22)}$. Diante disso, o processo de trabalho não deve se basear apenas em protocolos, normas e rotinas, para a realização da assistência, mas, sobretudo, disponibilizar um cuidado que considere o respeito ao outro e à dignidade humana ${ }^{(19)}$.

Os participantes manifestaram ainda que cuidar, nesse contexto, faz com que se sintam realizados ante a melhora do quadro de saúde dos pacientes e em ter podido contribuir de alguma forma. Não obstante, revelaram que atuar nessa área possibilita-lhes um aprendizado diário, uma vez que compartilham o impacto que 0 adoecimento mental traz para a vida do indivíduo e sua família, levando-os a evoluir também como ser humano.

"Para mim significa muito, pois ao ver o paciente saindo do hospital me agradecendo e dizendo que minha ajuda foi ótima para seu tratamento, dizendo que foi muito bom estar conosco compartilhando um pouco de sua história de vida, revelando-nos que seguirá o tratamento corretamente é muito gratificante" (P7).

"Significa aprendizado constante principalmente no âmbito pessoal, apesar das dificuldades regras e normas impostas, me sinto realizada diante da ajuda que ofereço a eles" (P8).

Verificou-se que os significados obtidos com as vivências de cuidar no contexto hospitalar tem trazido benefícios tanto ao profissional, quanto as pessoas que recebem a assistência. Além disso, observou-se que os profissionais têm utilizado aptidões profissionais e pessoais, facilitando $o$ atendimento humanizado $e$ qualificando o cuidado prestado.

\section{CONSIDERAÇÕES FINAIS}

A análise dos relatos possibilitou compreender como os profissionais da equipe multiprofissional percebem e vivenciam o cuidado ao indivíduo mentalmente adoecido, identificando que suas práticas profissionais ainda estão pautadas na insegurança e na exposição a situações arriscadas, refletindo, de certo modo, em um estigma ao paciente dependente químico, e distanciando-o dos demais transtornos mentais. Levando em consideração a importância desses resultados, sugerem-se reflexões acerca da formação em educação em saúde ofertadas aos profissionais de hospitais psiquiátricos e de como ela é compreendida por eles.

Não obstante, evidencia-se a falta de experiência dos profissionais com o paciente psiquiátrico, baixa remuneração, sobrecarga de tarefas, em razão do número reduzido dos profissionais nos plantões. Diante desses fatos, é oportuno repensar a necessidade de outras fontes de financiamento para o suprimento de recursos humanos e materiais, com vistas a minimizar o excesso de carga de atividades a serem executadas e valorização do trabalho realizado pelos profissionais.

Apesar de inúmeros desafios relatados, compreende-se que a assistência e o cuidado percebido e vivenciado no hospital psiquiátrico têm produzido nos profissionais sentimentos de gratidão e satisfação, sobrepondo-se, por vezes, aos desafios experienciados. Esse contexto tem ainda possibilitado à equipe atentar para o impacto da doença na vida do indivíduo e família e, produzido importante crescimento pessoal.

Como limitação do estudo, destacam-se a realização em um único hospital psiquiátrico, de modalidade filantrópica e de uma região do Estado do Paraná, com características singulares. Apesar disso, compartilha de características similares a outros estudos e permitiu dar voz aos profissionais diante do contexto que vivenciam e que podem ser semelhantes ao de outros profissionais de equipes de saúde mental.

\section{REFERÊNCIAS}

1- Brasil. Ministério da Saúde. Saúde mental. Brasília: Ministério da Saúde, 2013. (Cadernos de Atenção Básica, no 34).

2- Brasil. Ministério da Saúde. Portaria no 3.588, de 21 de dezembro de 2017. Altera as Portarias no 3 e no 6 de dispor sobre a rede de atenção psicossocial, e dá outras providências. Diário Oficial da União 2017. Disponível em: https://bvsms.saude.gov.br/bvs/saudelegis/gm/2 017/prt3588 $22 \quad 12 \quad$ 2017.html 
3- Brasil. Ministério da Saúde. Lei no 10.216, de 6 de abril de 2001. Dispõe sobre a proteção e os direitos das pessoas portadoras de transtornos mentais e redireciona o modelo assistencial em saúde mental. Diário Oficial da União 2001. Disponível em: http://www.planalto.gov.br/ccivil 03/leis/leis 20 01/l10216.htm.

4- Lara APM, Volpe FM. Evolução do perfil das internações psiquiátricas pelo Sistema Único de Saúde em Minas Gerais, Brasil, 2001-2013. Ciênc Saúde Coletiva 2019;24(2):659-68. DOI: 10.1590/141381232018242. 146520171

5- Brolese DF, Lessa G, Santos JLG, Mendes JS, Cunha KS, Rodrigues J. Resilience of the health team in caring for people with mental disorders in a psychiatric hospital. Rev Esc Enferm USP 2017;51:1-8. DOI: $\quad$ 10.1590/s1980220x2016026003230

6- Pessoa Júnior JM, Santos RCA, Clementino FS, Oliveira KKD, Miranda FAN. Mental health policy in the context of psychiatric hospitals: Challenges and perspectives. Esc Anna Nery 2016;20(1):83-9. DOI: 10.5935/1414-8145.20160012

7- Alves SR, Santos RP, Oliveira RG, Yamaguchi MU. Serviços de saúde mental: percepção da enfermagem em relação à sobrecarga e condições de trabalho. J Res Fundam Care Online 2018;10(1):25-9. DOI: $\quad$ 10.9789/21755361.2018.v10i1.25-29

8- Bardin L. Análise de conteúdo. São Paulo: Edições 70; 2011.

9- Lean M, Leavey G, Killaspy H, Green N, Harrison I, Cook S, et al. Barriers to the sustainability of an intervention designed to improve patient engagement within NHS mental health rehabilitation units: $A$ qualitative study nested within a randomised controlled trial. BMC Psychiatry 2015;15(209):1-10. DOI: 10.1186/s12888-015-0592-9

10- Vieira GLC. Agressão física contra técnicos de enfermagem em hospitais psiquiátricos. Rev Bras Saude Ocup. 2017;42:1-9. DOI: 10.1590/2317$\underline{6369000004216}$

11- Wei CY, Chiou YW, Chien LY, Huang N. Workplace violence against nurses - prevalence and association with hospital organizational characteristics and health-promotion efforts: Cross-sectional study. Int J Nurs Stud. 2016;56:6370. DOI: 10.1016/j.ijnurstu.2015.12.012

12- Nunes JT, Sousa JERB, Neves NVP. Nursing care to users of psychoactive drugs in psychic suffering: Experience report. Rev Enferm UFPI 2017 [citado em 30 fev 2018]; 6(2):74-7.
Disponível

em: http://www.ojs.ufpi.br/index.php/reufpi/article/ view/5627/pdf.

13- Moraes L, Santos E, Reis H, Silva M, Vianna P, Kurimoto T. A loucura e a sua verdade em questão: Discursos de profssionais de enfermagem da atenção hospitalar. Revista Portuguesa de Enfermagem de Saúde Mental 2018;19:27-36. DOI: 10.19131/rpesm.0199

14- Melo JRF, Maciel SC. Representação social do usuário de drogas na perspectiva de dependentes químicos. Psicol: ciênc prof 2016;36(1):76-87. DOI: 10.1590/1982-3703000882014

15- Fernandes MA, Pereira RMF, Leal MSM, Sales JMF, Silva JS. Nursing care to psychiatric patients in a general hospital emergency. Rev Enferm UFPI 2016;5(2):41-5. DOI: 10.26694/reufpi.v5i2.5241

16- Torneiro VV, Fonseca SE, Souza AA. Structural debt analysis: A study of financing and investment policies in brazilian philanthropic hospitals. Braz. J. of Bus. 2019 [citado em 29 jul 2020]; 1(3):1670-83. Disponível

em: https://www.brazilianjournals.com/index.php/BJ B/article/view/4752/4382

17- Barnicot K, Summerhayes BI, Plummer E, Hart A, Barker C, Priebes S. Staff and patient experiences of decision-making about continuous observation in psychiatric hospitals. Soc Psychiatry Psychiatr Epidemiol. 2017;52(4):473-83. DOI: 10.1007/s00127-017-1338-4

18- Mistry $H$, Levack WMM, Johnson S. Enabling people, not completing tasks: Patient perspectives on relationships and staff morale in mental health wards in England. BMC Psychiatry 2015;15:307. DOI: 10.1186/s12888-015-0690-8

19- Adorno AMNG, Martins CA, Mattos DV, Tyrrell MAR, Almeida CCOF. Hospital management as a care tool. Rev Enferm UFPE 2017;11(8):314350. DOI: 10.5205/reuol.11064-98681-4ED.1108201720

20- Rocha FLR, Gaioli CCLO, Camelo SHH, Mininel VA, Vegro TC. Organizational culture of a psychiatric hospital and resilience of nursing workers. Rev Bras Enferm 2016;9(5):817-24. DOI: 10.1590/0034-7167.2016690501

21- Sebergsen K, Norberg A, Talseth AG. Confirming mental health care in acute psychiatric wards, as narrated by persons experiencing psychotic illness: An interview study. BMC Nurs. 2016;15:3. DOI: 10.1186/s12912-016-0126-x

22- Pessoa Júnior JM, Santos RCA, Clementino FS, Nascimento EGC, Miranda FAN. Mental health education and professional practice in the psychiatric hospital. Texto Contexto Enferm. 
2016;25(3):1-7.

Nota: Este trabalho faz parte de uma Monografia de Final de Curso.

Recebido em: $24 / 03 / 2020$

Aprovado em: 22/08/2020

Endereço de correspondência:

Bárbara Pereira da Rocha

Rua Viela Simão Romeiro, n 1298, Vila Esperança, Maringá, Paraná.

E-mail: barbarar_b_q@hotmail.com 